\title{
O jogo de espelhos de Machado e Rosa
}

Luiz Romero de Oliveira

Faculdade Estácio de Sá de Vitória Universidade Federal do Espírito Santo

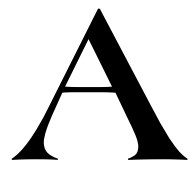

pesar da grande fortuna crítica das obras de Guimarães Rosa e Machado de Assis, seus textos ainda mantêm forte se nos permitirmos enveredar nos labirintos que os constituem. Esses dois grandes escritores permanecem entre aqueles que conseguem extrapolar territórios e temporalidade, conservando em seus escritos um traço que, segundo Clément Rosset em A lógica do pior, é característico do pensamento trágico: a resistência às interpretações. Seus textos apontam-nos cenas que não se fecham em um sentido, mas, ao contrário, abrem-nos portas para indefinidas possibilidades de leituras. Essas são razões mais que suficientes para retomar (sem receio de ser repetitivo) dois de seus contos, a saber, "O espelho", de Rosa, e "O espelho: esboço de uma nova teoria da alma humana”, de Machado. Para não correr o risco de nos perdermos em suas inúmeras possibilidades de leitura, será necessário tecer um fio (como o de Ariadne) que mantenha um trajeto relativamente fixo e nos ajude a evitar as armadilhas que, às vezes, os olhares sobre o texto produzem. O fio condutor será delimitado, então, por três elementos intimamente relacionados nos dois contos: o espelho, a imagem e o olhar.

Antes, porém, de nos lançarmos aos aspectos frisados acima, convém refletirmos sobre a narrativa dos dois autores, numa tentativa de, mesmo que rapidamente, observarmos elementos que podem aproximar suas poéticas. 
As estórias, Guimarães Rosa as queria oblíquas ante o engenho "estadado", ante as convenções oficiais que as tornam História. Tal visão é assumida pelo autor das Primeiras estórias no primeiro prefácio/conto de Tutaméia, "Aletria e hermenêutica": "A estória não quer ser história. A estória, em rigor, deve ser contra a História. A estória, às vezes, quer-se um pouco parecida à anedota”. ${ }^{1}$ Essa aproximação da estória ao chiste confere um estatuto especial à primeira: a possibilidade de abalar a ordem como faz o supra-senso do riso, permitindo à língua recuperar sua vida e - eis o esforço confesso rosiano - reanimá-la, reinstalá-la no movimento vital com a pureza das águas de uma nascente.

A preocupação de Guimarães Rosa pode ser aproximada daquilo que também é explícito nos textos machadianos: a "realidade" pretensamente uniformizada é sutilmente minada pelas narrativas desses autores que revelam a plástica relatividade da existência. Ambos, Guimarães Rosa e Machado de Assis, contam estórias que revelam o dilema do homem como criador e, em vários momentos, dominados pela criação: o homem alienado em suas próprias construções. Escapando das estereotipias da História oficial, nossos "heróis" nos permitem outras plagas, mais amplas, em suas estórias.

As Primeiras estórias, quarenta anos depois de sua primeira publicação, recentemente lidas e relidas, são "como do assoprado das cinzas e esplendição da brasa". ${ }^{2}$ Os olhos do leitor revolvem o carvão da escrita acendendo uma outra cena que propõe "realidade superior e dimensões para mágicos novos sistemas de pensamento"3 escapando às estereotipias cotidianas.

A tarefa de Guimarães Rosa - restituir a linguagem à vida - é consonante à observação de Walter Benjamin sobre a narrativa como resistência à estereotipagem da existência. Contar estórias, segundo este último, é uma habilidade que tem sido perdida no decorrer do

\footnotetext{
${ }^{1}$ ROSA, 2001. p. 7.

${ }^{2}$ ROSA, 2001. p. 99.

${ }^{3}$ ROSA, 2001. p. 7.
} 
tempo - reduz-se o número de contadores de estórias - por conta das alterações ocorridas no cenário da civilização européia nos últimos trezentos anos. A narrativa, na modernidade, é substituída pela informação, isto é, busca-se explicar os acontecimentos. Ainda segundo Benjamin, "metade da arte narrativa está em evitar explicações" e permite ao leitor a liberdade de "interpretar a história como quiser". ${ }^{4}$ Os "mestres das palavras", para utilizar a expressão de Françoise Hartog em O espelho de Heródoto, são aqueles que usam de "procedimentos lingüísticos que, em certos casos, conseguem fazer ver". 5

As narrativas dos dois contos escolhidos para este ensaio confluem para um ponto em comum: mostrar o inesperado. Os oitenta anos que separam os dois textos permitem ainda pensar as nuances que influenciarão essas narrativas em seus respectivos períodos: a revelação da realidade como um jogo de máscaras, de construções imaginárias, em Machado, e a insistência numa busca para além das máscaras que se mostra em Rosa.

Machado de Assis, circulando pelas ruas do Rio de Janeiro do século XIX, observa as contradições dos comportamentos e das crenças, ainda impregnados pelo romantismo e pelo positivismo cientificista, inscrevendo-as de modo sutil e irônico na trama dos seus textos. Imerso nos ares críticos do seu tempo, Machado salienta em "O espelho" um aspecto que será posteriormente desenvolvido por Sigmund Freud, a saber, a inconsistência do eu - que a partir do texto freudiano será visto apenas como uma das instâncias do aparelho psíquico. Tal assertiva abala a pressuposição cartesiana, expressa na máxima cogito, ergo sum, de um sujeito plenamente consciente de si e do mundo.

O espelho de Machado, assim como o de Guimarães Rosa, surge como uma janela através da qual se vislumbra a divisão do sujeito moderno - uma outra cena que escapa ao olhar desavisado.

${ }^{4}$ BENJAMIN, 1985. p. 203.

${ }^{5}$ HARTOG, 1999. p. 24. 
No conto machadiano o cerne é a experiência de Jacobina, o quinto e casmurro personagem da trama, que é chamado a expor sua opinião sobre as características da alma do homem. Esse personagem, em princípio apresentado como uma mera figura que comporia o cenário, ergue-se do seu silêncio e se presentifica em um discurso impactante, exigindo de todos a irrestrita atenção, e narra a estranha experiência que o levou a estabelecer a tese que o homem possuiria duas almas, uma interna e outra externa, assim definidas:

A alma exterior pode ser um espírito, um fluido, um homem, muitos homens, um objeto, uma operação. Há casos, por exemplo, em que um simples botão de camisa é a alma exterior de uma pessoa; - e assim também a polca, o voltarete, um livro, uma máquina, um par de botas, uma cavatina, um tambor, etc. Está claro que o ofício dessa segunda alma é transmitir a vida, como a primeira; as duas completam o homem, que é, metafisicamente falando , uma laranja". ${ }^{6}$

Essas "almas", as duas metades da laranja, se usarmos algumas idéias freudianas, poderiam ser pensadas como a imbricação de um objetivo e um objeto de desejo - a conjugação de um ideal com um objeto qualquer, que o próprio Jacobina explicita em sua natureza múltipla e parcial (a polca, o voltarete, um livro, uma máquina, um par de botas, uma cavatina, um tambor, etc), necessitando de aspectos suplementares para que seja elevado ao estatuto de "alma". Por essa via é salientado o jogo existente entre o desejo e o outro que, enfim, funcionará como um espelho.

A experiência de Jacobina se inicia quando ele é nomeado alferes. As honrarias que, devido a sua nova função, passam a conferir-lhe amigos, conhecidos e parentes, servem como gatilho para o desencadeamento de um processo em que a imagem do jovem personagem fica solidamente ligada ao seu posto. $O$ conto de Machado, entretanto, nos mostra a fragilidade da idealização de Jacobina, utilizando como recurso narrativo o afastamento de todos os que de algum modo servissem como espelho para o olhar do

${ }^{6}$ MACHADO DE ASSIS, 1999. p. 402. 
narcísico personagem. Assim sendo, a sua tia e madrinha D. Marcolina, dona do sítio no qual nosso herói se encontrava (e também responsável por grande parte da adulação de que Jacobina era servido), é chamada para cuidar de uma filha adoentada, iniciando o processo de inquietação do personagem: "Confesso-lhes que desde logo senti uma grande opressão, alguma coisa semelhante ao efeito de quatro paredes de um cárcere, subitamente levantadas em torno de mim. Era a alma exterior que se reduzia"?

A narrativa machadiana prossegue mostrando o olhar desassossegado de Jacobina diante da constatação de um eu dividido pela derrisão do que, até então, se mostrava como plenitude: sua imagem de alferes. Após o afastamento da tia, fogem os escravos; e até mesmo a possibilidade do retorno do cunhado da tia é afastada. Desamparado pela especularidade a que o outro, agora ausente, servia de anteparo, Jacobina é deixado à beira de abissal angústia:

Minha solidão tomou proporções enormes. Nunca os dias foram mais compridos, nunca o sol abrasou a terra com uma obstinação mais cansativa. As horas batiam de século a século, no velho relógio da sala, cuja pêndula, tic-tac tic-tac, feria-me a alma interior, como um piparote contínuo da eternidade. ${ }^{8}$

A imagem da "alma externa" que se arruinava implica a desestabilização da ordem "natural" das coisas - tempo e espaço perdiam suas dimensões cotidianas - e afeta até sua "alma interna", aquela que ainda lhe permitia, nos momentos de sono, algum consolo: "Nos sonhos fardava-me orgulhosamente no meio da família e dos amigos, que me elogiavam o garbo, que me chamavam de alferes".

Abalado em suas convicções, Jacobina evita até olhar no espelho que sua tia especialmente lhe deixara, pois aquilo que, antes, poderia mostrá-lo em sua integridade de alferes, surge como

\footnotetext{
7 MACHADO DE ASSIS, 1999. p. 406.

${ }^{8}$ MACHADO DE ASSIS, 1999. p. 407.

${ }^{9}$ MACHADO DE ASSIS, 1999. p. 408.
} 
uma ameaça de revelá-lo fragmentado: "Não era abstenção deliberada, não tinha motivo; era um impulso inconsciente, um receio de achar-me um e dois ao mesmo tempo, naquela casa solitária". ${ }^{10}$

O receio de Jacobina em breve se mostrará infundado. Ao fitar o espelho o seu estranhamento vai além do esperado: nem um, nem dois - a sua imagem se perdera, restando-lhe o homogêneo do caos: "O próprio vidro parecia conjurado com o resto do mundo; não me estampou a figura nítida e inteira, mas vaga, esfumada, difusa, sombra de sombra". ${ }^{11}$

O abalo causado pelo desencontro não impede que o olhar de Jacobina, furtivo, vez e outra, ainda busque no espelho algo que restitua a sua integralidade, mas este lhe revela apenas "a mesma difusão de linhas, a mesma decomposição de contornos". ${ }^{12} \mathrm{O}$ sofrimento do personagem só se reduz quando, "por uma inspiração inexplicável", ${ }^{13}$ lembra-se de vestir o uniforme de alferes (aquilo que o consolava em seus sonhos nas solitárias noites do sítio retorna como inspiração) possibilitando ao espelho, enfim, mostrá-lo em sua alma exterior. Ao fim do relato do personagem há um aspecto que não pode ser desprezado: a sua saída de cena é como um retorno ao silêncio inicial - cessado o discurso o sujeito se esvai deixando os seus ouvintes estupefatos. Por essa via Machado nos mostra um sujeito que se constrói e desaparece como um efeito de discurso.

Depreende-se desse conto de Machado o efeito especular que o outro comporta, e é salientada a formação discursiva como o topos em que as ficções pessoais (as "almas" de Jacobina) são erigidas o eu se constrói a partir dos elogios proferidos por terceiros nos quais se ancoram o desejo do personagem. O espelho surge, nesse contexto, com uma função inesperada: mostrar, para além da imagem organizada do ego, o ilimitado do real causando profundo

\footnotetext{
${ }^{10}$ MACHADO DE ASSIS, 1999. p. 409.

${ }^{11}$ MACHADO DE ASSIS, 1999. p. 409.

${ }^{12}$ MACHADO DE ASSIS, 1999. p. 410.

${ }^{13}$ MACHADO DE ASSIS, 1999. p. 410.
} 
estranhamento ao narrador. Machado mostra uma cena sem evitar ao olhar do leitor as frinchas que surgem e abalam princípios considerados, em determinados momentos, como verdades sólidas e absolutas.

A relatividade dos valores culturais, dos conceitos morais e científicos é algo que tem, nos textos machadianos, um sutil, porém cruel, espelho. Se se pensar a arte como um "espelho" para a realidade, com certeza essa realidade não se reduzirá aos pontos que a óptica física ensina na escola: as imagens produzidas pelo espelho/ arte são paradoxalmente iconoclastas; uma iconoclastia emergente nas diversas expressões das vanguardas do início do século XX. As mudanças estéticas daí advindas, envolvendo o uso extremado das possibilidades da linguagem, terão em Guimarães Rosa, em meados do século XX, um representante que não se furtará à tarefa de experimentar os efeitos que a plasticidade das palavras propicia.

Deixando-se guiar, o escritor mineiro segue, aparentemente à deriva, o mais distante possível com o fio da linguagem que, enfim, mostra-se um caudaloso rio cujas margens perdem-se de vista. A vida, intrinsicamente linguagem, nos é revelada em amplitude não dimensionada, podendo ser lida "não literalmente, mas em seu supra-senso". ${ }^{14}$ O homem moderno, segundo Rosa, diante dessa amplitude incomensurável, tem buscado restringir tal dimensão estreitando suas margens com pressupostos de uma lógica racional positivista, cuja maior conseqüência seria o estancamento da vida. Rosa, ao apresentar em seus textos o ilógico e a imprevisibilidade da existência, aponta a necessidade de se arriscar em trajetos inusitados e afirma o acaso da vida, o novo de cada instante, inscrito numa linguagem que para cumprir essa função torna-se puro devir.

A imagem do devir, em Guimarães, pode ser encontrada nas águas dos rios que atravessam a sua obra. Rios que, como o de Heráclito, em constante movimento, nunca são os mesmos. Imagem que recupera uma inocência perdida para o homem moderno que

${ }^{14}$ ROSA, 2001. p. 8. 
se fixa à margem, como faz o filho/narrador em "A terceira margem do rio”, buscando a lógica do ilógico e não suportando quando este último se lhe apresenta. A face bizarra do mal-estar da sociedade moderna, como nos sugere Freud, se revela diante do indizível (a Coisa freudiana), aquilo que em sua inércia a-significante traz a vertigem da morte, insuportável presença que o olhar contemporâneo evita e, conseqüentemente, desfigura a dimensão do próprio rio/vida que corre e tudo arrasta. Guimarães Rosa se propõe a tarefa de lançar-se nessas águas e sentir seu infinito movimento (espírito trágico do sertanejo) na tentativa de escapar da estagnação que o olhar lógico impõe ao rio. É diante desse indizível, e com ele, que Guimarães engendra sua poética: "o escritor deve se sentir à vontade no incompreensível", ${ }^{15}$ afirma em seu diálogo com Günter Lorenz, e acrescenta, citando Goethe, "a poesia é a linguagem do indizivel". ${ }^{16}$

Sob a verdade que a história comportaria circula célere aquilo que Guimarães salienta como o ilógico da existência. Pensar as "verdades" da vida, como sugere no terceiro prefácio de Tutaméia, "Nós, os temulentos", não implica grandes vôos filosóficos. É na simplicidade do cotidiano, através dos passos trôpegos do personagem Chico - num trajeto desconstrutor de pressupostos ontológicos - que o narrador nos guia do serao não-ser. A dimensão paradoxal do sentido, de radical estranhamento, tem seu ápice quando Chico, diante do espelho do armário, não se identifica:

E, avançando contra o armário, e vendo o outro arremeter também ao seu encontro, assestou-lhe uma sapatada, que rebentou com o espelbo nos mil pedaços de praxe. - Desculpe, meu velho. Também, quem mandou você não tirar os óculos? - O Chico se arrependeu. E, com isso lançou; tumbou-se pronto na cama; e desapareceu de si mesmo. ${ }^{17}$

${ }^{15}$ ROSA, 1991. p. 88.

${ }^{16}$ ROSA, 1991. p. 91.

${ }^{17}$ ROSA, 2001. p. 118. 
Eis-nos, então, diante do espelho. Um curioso espelho que desdobra as imagens e as transfigura, erigindo uma nova percepção de seus efeitos e deslocando-o para um campo realmente inovador. Seguindo o caminho que o espelho de Machado nos abre em 1882, encontraremos, oitenta anos depois, o conto "O espelho" de Guimarães Rosa explorando regiões não sondadas por Machado.

O narrador do conto do consagrado autor mineiro convida o leitor ao diálogo, tentando manter um ar cientificista no seu discurso (para produzir efeito similar Machado situou seu personagem num grupo de diletantes filósofos metafísicos) e buscando evitar a feição literária da narrativa: "Desculpe-me, não viso a efeitos de ficcionista, inflectindo de propósito, em agudo, as situações"18 - estratégia discursiva que joga ironicamente com a racionalidade científica ao mesmo tempo em que envolve o leitor com a "verdade" do seu discurso. Percebe-se com facilidade a irônica postura de Rosa diante do discurso científico expressa no objeto "inflectido", pouco palpável, de caráter excessivamente subjetivo, levado à discussão: a imagem que escapa às leis da física óptica.

Convém aceitarmos o convite do narrador rosiano e seguí-lo no relato de sua experiência que nos mostra a ordem dos fatos investida de mistérios: "Quando nada acontece, há um milagre que não estamos vendo". ${ }^{19}$ Considerando-se o caráter mutável da vida, as formas diversas de espelhos e a própria limitação do aparelho perceptivo humano, prossegue o narrador, como garantir que a imagem refletida pelo espelho é fidedigna? O especular comporta ainda uma carga semântica que abrange em seu espectro a racionalidade e a ilusão: abre-se um leque que parte do diáfano e transparente para alcançar a minúcia teórica, o raciocínio, o risco do jogo e, enfim, o uso de recursos especiais para iludir alguém em proveito próprio. Veremos que, no conto de Guimarães Rosa, o percurso narrativo envolve todas essas instâncias, configurando-o assim, como um espelho d'escrito.

\footnotetext{
${ }^{18}$ ROSA, 2001. p. 126.

${ }^{19}$ ROSA, 2001. p. 119.
} 
Escudado em seu discurso científico a la Poe (observem, por exemplo, os contos "Uma descida ao Maelstrom" e "O jogador de xadrez de Maelzel", do autor americano) o narrador desmonta as possíveis opiniões favoráveis à fidedignidade do espelho e afirma: "Os olhos, por enquanto, são a porta do engano; duvide deles, dos seus, não de mim. Ah, meu amigo, a espécie humana peleja para impor ao latejante mundo um pouco de rotina e lógica, mas algo ou alguém de tudo faz frincha para rir-se da gente...." 20

Desviando-se do plano da lógica física, como Machado, Rosa nos endereça a uma outra cena: o espelho, o utensílio, é anteparo não apenas para a imagem, mas também, e principalmente, para o olhar. O narrador, como o poeta de A divina comédia, nos guia com sua lanterna até a frincha que existe entre a imagem e o espelho.

Prosseguindo no trajeto, o narrador persiste jogando com o tom cientificista ao interrogar as deformadas imagens que, por vezes, o espelho insiste em nos mostrar:

Porque, neles, às vezes, em lugar de nossa imagem, assombra-nos alguma outra e medonha visão. Sou, porém, positivo, um racional, piso o chão a pés e patas. Satisfazer-me com fantásticas nãoexplicações? - Jamais. Que amedrontadora visão seria então aquela? Quem o monstro? ${ }^{21}$

O narrador, após trafegar entre o mito e a racionalidade, relata o seu encontro com a estranheza:

Foi num lavatório de edifício público, por acaso. Eu era moço, comigo contente, vaidoso. Descuidado, avistei... Explico-lhe: dois espelhos - um de parede, o outro de porta lateral, aberta em ângulo propício - faziam jogo. E o que enxerguei, por instante, foi uma figura, perfil humano, desagradável ao derradeiro grau, repulsivo senão hediondo. Deu-me náusea, aquele homem, causava-me ódio e susto, eriçamento, espavor. E era - logo descobri... era eu, mesmo! O senhor acha que eu algum dia ia esquecer essa revelação? ${ }^{22}$

\footnotetext{
${ }^{20}$ ROSA, 2001. p. 121.

${ }^{21}$ ROSA, 2001. p. 121.

${ }^{22}$ ROSA, 2001. p. 122.
} 
Essa cena diante do espelho (que em muito se aproxima do relato de Freud em "O estranho") será o ponto de aproximação entre Machado e Rosa, mas também será o limite que os separará. Jacobina, em sua experiência, espera recuperar a sua imagem perdida, já o narrador rosiano se lança na tarefa de buscar o que a imagem recobre: "Desde aí, comecei a procurar-me - ao eu por trás de mim - à tona dos espelhos, em sua lisa, funda lâmina, em seu lume frio". 23

Nesse trajeto para além da imagem, através do espelho, o narrador descobre, permanente, o olhar - objeto de obscura e abissal natureza: "Soube-o: os olhos da gente não têm fim. Só eles paravam imutáveis, no centro do segredo. Se é que de mim não zombassem, para lá de uma máscara. Porque, o resto, o rosto, mudava permanentemente". ${ }^{24}$

O trabalho do narrador, como o do arqueólogo, é retirar camadas de máscaras revelando outros aspectos dos seres humanos: somos animais, cada qual com seu traço predominante. O narrador indica que as multidões estão prenhes de ovinos e eqüinos, presas diletas dos predadores entre os quais se situa o narrador: "Meu sósia inferior na escala era, porém - a onça". ${ }^{25}$ Eis uma interessante imagem para o poeta/escritor: o predador que surpreende suas diletas vítimas (leitores e não-leitores) com o inesperado que surge a cada instante no labirinto do texto. Mas o interesse do narrador sobre esse aspecto é curto. Dimensões maiores estão por vir: "E, então, eu teria que, após dissociá-los meticulosamente, aprender a não ver, no espelho, os traços que em mim recordavam o grande felino. Atirei-me a tanto". ${ }^{26}$

O experimentador, nada ortodoxo, não recusa métodos para alcançar seu intento. Ele conjuga "exercícios espirituais dos jesuítas"

\footnotetext{
${ }^{23}$ ROSA, 2001. p. 123.

${ }^{24}$ ROSA, 2001. p. 123.

${ }^{25}$ ROSA, 2001. p. 124.

${ }^{26}$ ROSA, 2001. p. 124.
} 
com experimentos perceptivos gestaltistas (gradação de luzes, lâmpadas coloridas, etc.), mas privilegia, como Jacobina em alguns momentos, o olhar de soslaio, com o canto dos olhos: "Mas, era principalmente no modus de focar, na visão parcialmente alheada, que eu tinha de agilitar-me: o olhar não-vendo. Sem ver o que, em meu rosto, não passava de reliquat bestial". ${ }^{27}$

Se Jacobina fica prostrado após ser tomado de assalto em sua experiência de desagregação, em Rosa encontramos o narrador, após seu inusitado desencontro, voluntariamente buscando repetir o acontecido, como um "cientista", para entender a experiência vivida. O narrador, imbuído em sua tarefa, elimina gradativamente os traços percebidos na imagem especular como se fossem reminiscências e projeções do seu psiquismo (heranças de pais e avós, idéias e sugestões de outrem - como já observara Jacobina no conto de Machado) até chegar a formas abstratas e difusas. Mas o esforço exigido pela tarefa leva ao desgaste físico, forçando o narrador a abandonar, por meses, seus experimentos diante do espelho.

Passado o tempo, esquecido de sua tarefa anterior, o narrador se depara com um espelho no qual nada vê - sua imagem lhe escapa: "Eu não tinha formas, rosto? Apalpei-me, em muito. Mas, o invisto. $\mathrm{O}$ ficto. $\mathrm{O}$ sem evidência física. Eu era - o transparente contemplador?... Tirei-me. Aturdi-me, a ponto de me deixar cair na poltrona". ${ }^{28}$

Deslocado de sua imagem, o narrador seria apenas olhar? Eis o "transparente contemplador". A busca de uma essência o levou ao vazio de um olhar não-visto: "E, o que tomadamente me estarreceu: eu não via meus olhos. No brilhante e polido nada, não se me espelhavam nem eles!” ${ }^{29}$ A percepção do narrador, nesse momento, se aproxima da observação feita por Jacques Lacan sobre o olhar:

\footnotetext{
${ }^{27}$ ROSA, 2001. p. 124-125.

${ }^{28}$ ROSA, 2001. p. 126.

${ }^{29}$ ROSA, 2001. p. 126.
} 
Uma vez que o sujeito tenta acomodar-se a esse olhar, ele se torna esse olhar, esse objeto punctiforme, esse ponto evanescente, com o qual o sujeito confunde o seu próprio desfalecimento. Também, de todos os objetos nos quais o sujeito pode reconhecer a dependência em que está no registro do desejo, o olhar se especifica como inapreensível. ${ }^{30}$

E Lacan, citando Sartre, acrescenta a seguir: "No que estou sob o olhar, escreve Sartre, não vejo mais o olho daquele que me olha, e se vejo esse olho, é então esse olhar que desaparece". ${ }^{31}$ O narrador do conto de Guimarães Rosa se vê olhando o seu olhar, e isso produz um deslocamento que o insere em um campo que escapa às imagens cotidianas e produz a sensação de estranhamento:

E a terrível conclusão: não haveria em mim uma existência central, pessoal, autônoma? Seria eu um... des-almado? Então, o que se me fingia de um suposto $e u$, não era mais que, sobre a persistência do animal, um pouco de herança, de soltos instintos, energia passional estranha, um entrecruzar-se de influências, e tudo mais que na impermanência se indefine? Diziam-me isso os raios luminosos e a face vazia do espelho - com rigorosa infidelidade. E, seria assim, com todos? Seríamos não muito mais que as crianças - o espírito de viver não passando de ímpetos espasmódicos, relampejados entre miragens: a esperança e a memória. ${ }^{32}$

A "rigorosa infidelidade" do espelho se dá para com as estereotipias do que se define cotidianamente como $\mathrm{eu}$. Os espelhos poéticos de Rosa e Machado revelam o inesperado no lugar do ansiado pela cultura lógica racionalista - um eu que tudo controla - e propiciam o questionamento da própria existência: "Você chegou a existir?"33 pergunta o narrador rosiano ao leitor, deixando-o diante de uma incógnita que pode representar o portal de acesso às esferas

\footnotetext{
${ }^{30}$ LACAN, 1988. p. 82.

${ }^{31}$ LACAN, 1988. p. 82.

${ }^{32}$ ROSA, 2001. p. 126.

${ }_{33}^{3}$ ROSA, 2001. p. 128.
} 
infernais. Ao impasse que aí se instala, surge uma pequena luz: o que se vislumbrava como a face do desamparo poderia ser, de fato, uma nova senda a trilhar. Uma vereda marcada pela inocência da criança, que Guimarães também encontrará no sertanejo, que tudo experimenta - para quem o novo surge a cada instante.

São coisas que não se devem entrever; pelo menos, além de um tanto. São outras coisas, conforme pude distinguir, muito mais tarde - por último - num espelho. Por aí, perdoe-me o detalhe, eu já amava - já aprendendo, isto seja, a conformidade e a alegria. E... Sim, vi, a mim mesmo, de novo, meu rosto, um rosto; não este, que o senhor razoavelmente me atribui. Mas o ainda-sem-rosto - quase delineado, apenas - mal emergindo, qual uma flor pelágica, de nascimento abissal... E era não mais que: rostinho de menino, só. Só..$^{34}$

Esta citação nos mostra o movimento da inocência perante a vida - uma inocência "sem consciência do pecado original", ${ }^{35}$ sem culpa - se aproximando da alegria afirmativa salientada por Gilles Deleuze como essência do trágico em Nietzsche que "compreende a existência a partir de um instinto de jogo". "Uma criança que brinca frente ao eterno devir - o infinito sempre surpreendente; o caminho para a alegria de, ao jogar com as palavras, descobrir "sempre um novo pedaço do infinito". ${ }^{37}$

\footnotetext{
${ }^{34}$ ROSA, 2001. p. 127.

35 ROSA, 1991. p. 94.

${ }^{36}$ DELEUZE, 1976. p. 19.

37 ROSA, 1991. p. 72.
} 


\section{Referências Bibliográficas}

ASSIS, Joaquim Maria Machado. Contos: uma antologia. Sel., intr. e notas de John Gledson. 2. ed. São Paulo: Companhia das Letras, 2001.

BENJAMIN, Walter. Magia e técnica, arte e política. São Paulo: Brasiliense, 1985.

COUTINHO, Eduardo (Org.). Guimarães Rosa. 2.ed. Rio de Janeiro: Civilização Brasileira, 1991.

FREUD, Sigmund. O estranho. In: Obras psicológicas completas. Rio de Janeiro: Imago, 1977. v. 17, p. 275-318.

. O mal-estar da civilização. In: . Obras psicológicas completas. Rio de Janeiro: Imago, 1977. v. 21, p. 81-171.

HARTOG, Françoise. O espelho de Heródoto:ensaio sobre a representação do outro. Belo Horizonte: Ed. UFMG, 1999.

LACAN, Jacques. O seminário, livro 11: os quatro conceitos fundamentais da psicanálise. Rio de Janeiro: Jorge Zahar, 1988.

OLIVEIRA, Luiz Romero. Machado e o trágico. In: . Vale a escrita?: poéticas, cenas e tramas da literatura. Vitória: PPGL-UFES, 2001.

. O espelho e algumas mulheres. In: IX SEMINÁRIO NACIONAL MULHER \& LITERATURA, 2001, Belo Horizonte. Anais..., UFMG, agosto de 2001.

ROSA, João Guimarães. O espelho. In: Primeiras estórias. Rio de Janeiro: Nova Fronteira, 2001. p. 119-128.

.Aletria e hermenêutica. In: Janeiro: Nova Fronteira, 2001. p. 7-17.

Nós, os temulentos. In: Tutaméia: terceiras estórias. Rio de Janeiro: Nova Fronteira, 2001. p. 115-118.

ROSSET, Clement. A lógica do pior. Rio de Janeiro: Espaço e Tempo, 1989. 


\section{Resumo}

Este artigo objetiva refletir sobre como é abordado o enigma que se configura, a partir do século XIX, em torno do que se convenciona chamar de "eu" e de "realidade", nos contos "O espelho: esboço de uma nova teoria da alma humana", de Machado de Assis, e "O espelho", de Guimarães Rosa.

\section{Abstract}

The purpose of this essay is to speculate on approaches made since the $19^{\text {th }}$ century to the enigma deriving from such particular issues as the socalled "self" and "reality", by focussing this speculation on two shortstories by Brazilian authors Machado de Assis ( "O espelho: esboço de uma nova teoria da alma humana") and Guimarães Rosa ("O espelho") 